\title{
Recycling EVA Waste: An Opportunity For The Footwear Industry - Rheological Properties of EVA Waste Composites Using Torque Rheometry
}

\section{Z. Paiva Júnior}

Universidade Federal da Paraiba

\section{A. V. Mendonca}

Universidade Federal da Paraiba

F. C. Fim

Universidade Federal da Paraiba

Lucineide Balbino Silva ( $\square$ lucineide@ct.ufpb.br)

Universidade Federal da Paraiba https://orcid.org/0000-0002-8550-080X

\section{Research Article}

Keywords: Recycling, Rheological properties, FTIR, rubber composites

Posted Date: July 15th, 2021

DOI: https://doi.org/10.21203/rs.3.rs-665339/v1

License: (c) This work is licensed under a Creative Commons Attribution 4.0 International License. Read Full License

Version of Record: A version of this preprint was published at Journal of Polymers and the Environment on November 24th, 2021. See the published version at https://doi.org/10.1007/s10924-021-02332-x. 


\title{
Recycling EVA waste: an opportunity for the footwear industry - rheological properties of EVA waste composites using torque rheometry
}

\author{
C. Z. Paiva Júnior ${ }^{a}$, A. V. Mendonca ${ }^{b}$, F. C. Fim ${ }^{a}$, L. B. Silva ${ }^{a *}$
}

a'Universidade Federal da Paraíba, Graduate Program in Materials Science and Engineering - CEP: 58051-900, João Pessoa, PB, Brazil

bUniversidade Federal da Paraíba, Graduate Program in Civil Engineering - CEP: 58051900, João Pessoa, PB, Brazil

*Corresponding author: L. B. Silva <lucineide@ct.ufpb.br>

\begin{abstract}
Ethylene vinyl acetate blends (EVA-B) (at 19 and 28wt\% vinyl acetate) were supplied by the footwear industry, along with an industrial (reference) compound labeled EVA-ref. EVA waste is an industrial sub-product crosslinked (injection sprues and unused midsoles), that was particulate through a micronization process and labeled as EVA-w. The objective of the present work was to evaluate processability and rheological parameters (using torque rheometry) when adding EVA-w to EVA-B. The EVA-w particle size distribution was bimodal, with an average diameter of $53.06 \mu \mathrm{m}$, and volume (\%) D (10), D (50), and D (90) respectively equal to $12.47,31.83$, and $135.18 \mu \mathrm{m}$. However, this ample size distribution did not affect the composite mixing. FTIR-ATR analysis showed that no new crosslinking occurred after processing the composites. Low unit mixing energy $(\mathrm{Wu})$, and mechanical work (as represented by $\Delta \mathrm{T}$ values: torque stabilization temperature $\left(\mathrm{T}_{\text {stab }}\right)$ - test temperature $\left(\mathrm{T}_{\text {test }}\right)$ ) were required to mix the composites. Consequently, the dispersion of the EVA-w particles within the molten EVA$\mathrm{B}$ occurred during the first $3 \mathrm{~min}$ of mixing, making it easier. The sensibility to shearthinning behavior was more pronounced when adding EVA-w, especially at $25 \mathrm{phr}$. The $m$ parameter was smaller in the composites as compared to the EVA-ref, and when adding EVA-w at $35 \mathrm{phr}$, it showed a tendency to increase. The average shear stress $(\bar{\tau})$ of the 15 phr composite was similar to that of the EVA-ref compound. Yet for $25 \mathrm{phr}$, a higher value was observed. The adding of EVA-w made the non-Newtonian behavior of EVAB less pronounced. For all samples, the average viscosity $(\bar{\eta})$ decreased with average shear rate $(\bar{\gamma})$, revealing a pseudoplastic behavior.
\end{abstract}

Keywords: Recycling, Rheological properties, FTIR, rubber composites 


\section{Introduction}

Ethylene vinyl acetate compound (EVA) is a copolymer of ethylene and vinyl acetate available with the vinyl acetate levels typically in the range 10 to $40 \mathrm{wt} \%[1,2]$. Its structure is composed of both elastic and transition segments which respectively give EVA products elasticity and shape reversibility; being from soft (at high temperatures) to hard (at low temperatures) [2, 3]. Moreover, when vinyl acetate levels are higher than 30 $\mathrm{wt} \%$ an amorphous structure (due acetoxy group) hinders PE chain packing. The balance between amorphous and crystalline regions allows for a wide variety of applications: from soles and insoles in footwear, to melt adhesives, wine bottle closures, and cable coverings $[2,4,5]$.

The large production of shoes using EVA also generates expanded EVA waste, containing a permanent reticulated molecular structure, which is acquired during the vulcanization process. In turn, the crosslinked molecular chain of Eva alters its properties and flow capacity, prevents melt, and reprocessing, which makes it difficult to recycle [6-9]. Consequently, an increasing amount of EVA waste is sent from the industrial sector to landfills, aggravating local environmental problems [10]. However, by reutilization this industrial new products can be obtained [11]. Further, the high cost of managing wastes industry has led to alternative uses of EVA waste as a raw material. This, makes it possible to achieve a reduction in waste generation, economic and environmental gains as well due to sustainability manufacturing [12].

When Eva scraps are recycled in polymeric matrices, conventional processes are adopted. In the footwear industry, the recycling potential of these compounds has been investigated via mechanical properties [13,14]. Knowledge of the rheological properties of rubber products is important to optimize its commercial production, however few works can be found addressing rubber waste added to footwear rubbers. According to [15, 16], the dependence of the dispersed phase on the flow properties of the matrix can be assessed using reliable torque rheometric data where torque, rotor speed, and temperature are measured during mixing. These variables are converted into shear rate and shear stress through the mathematical proposals presented in Section 3 [17-19]. Therefore, the novelty and collaboration of the present work is studying the rheological properties using the torque rheometer to investigate the potential processability of EVA copolymer/crosslinked EVA waste composites.

Rheological studies for blends of rubber powders in the footwear industry using torque rheometric data are still scarce, and so the present work aims to determinate the 
rheological properties of EVA-ref (a formulation used in the local footwear industry) and its blends at 15, 25, and $35 \mathrm{phr}$ (parts per hundred rubber) with cross-linked expanded EVA-w waste. Torque rheometry and appropriate mathematical approaches were used. Using different rotor speeds $(20,30,40$, and $50 \mathrm{rpm})$, the average shear rate, average shear stress, and average viscosity, as well as a consistency index $(m)$, and a power law index $(n)$ were determined. In addition, granulometry and structural property by FTIRATR are also investigated.

\section{Materials and methods}

\section{Materials}

Vinyl ether-acetate copolymer blend (EVA-B), composed of composed of $19 \mathrm{wt} \%$ (3019PE) and 28wt\% vinyl acetate (HM728), were supplied by Braskem S/A. The ethylene butene copolymer (ENGAGE 7256) was provided by Dow Chemical Company. The compound labelled as EVA-ref was formulated and supplied by Indústria Alpargatas S/A - a shoes and sporting goods company, located in the city of João Pessoa. The formulations of both EVA-B and EVA-ref were constituted of: flux agent manufactured by Baerlocher Brazil S/A, peroxide type 1.3 Di (2-tert. Butyl Peroxide Isopropyl) Benzene with a purity of $40 \%$ manufactured by Retilox Química Especial LTDA, expansion agent (azodicarbonamide) manufactured by Proquitec-Indústria de Produtos Químicos e Representação S/A., calcium carbonate with $98 \%$ purity, manufactured by Fosquímica e Derivados LTDA, Zinc Oxide with 99\% purity and manufactured by Brasoxidos - Indústria Química LTDA. The micronized EVA waste (EVA-w) came from the twigs and unused material molded during the midsole injection (Fig. 1), both supplied by Indústria Alpargatas S/A. All formulations are shown in Table 1. The EVA-B composites with 15, 25 and 35 phr of EVA-w were supplied in thin sheets by the aforementioned industry, being cut into smaller pieces for later mixing in the torque rheometer.

\section{Preparation of the industry standard compound (EVA-ref)}

Initially, an intermediate compound (IC) consisting of 60 percentage by weight (wt $\%$ ) of injection sprues and unused midsole of EVA residues, and 40wt\% of EVA virgin resin with $28 \mathrm{wt} \%$ by weight of vinyl acetate was prepared. For this, the components were mixed using an industrial kneader type JKM-DK75-150HP manufactured by Jian Kwang Machine Industrial CO., LTD, at a temperature of $110^{\circ} \mathrm{C}$ for $540 \mathrm{~s}$ and mixing speed of 
$39 \mathrm{rpm}$ for front rotor and $30 \mathrm{rpm}$ for back rotor. After this stage of uniformity, the intermediate compound (IC) was moved using a conveyor belt until meeting an extruder type SM65-100HP manufactured by SonoMina Machinery Industries Co. LTD. Finally, the intermediate compound was fed into the extruder hopper and mixed at $85^{\circ} \mathrm{C}$ screw temperature, and a rotation speed of $27 \mathrm{rpm}$ to transform it into pellets. After this step, the $12 \mathrm{phr}$ of IC produced was added to the EVA-B blend (containing $41 \mathrm{phr}$ of $19 \mathrm{wt} \%$ EVA, and $24 \mathrm{phr}$ of $28 \mathrm{wt} \% \mathrm{EVA}$ ), in accordance with the formulation given in Table 1, which also contains the other components of all formulations. This mixture of the intermediate compound with the EVA-B blend corresponds to the standard compound (EVA-ref), which contains $8 \mathrm{phr}$ of the crosslinked EVA waste. It is worth mentioning that the EVA used in the preparation of the EVA-ref was not micronized.

\section{Micronization of reticulated EVA waste}

The waste from the injection sprues (Fig. 1a) and unused midsoles (Fig.1b) were ground in a knife mill (Plastimax). The crosslinked EVA particles (Fig.1c) were then inserted to the micronization machine (Alfa Mill L700) with a processing capacity of 20 $\mathrm{kg} / \mathrm{h}$ to produce the micronized waste (EVA-w) (Fig.1d).

\section{Preparation of EVA-ref and EVA-B/EVA-w composites}

The micronized waste (EVA-w) was added to the EVA-B blend at concentrations of 15, 25 and 35 phr (Per Hundred Rubber), as shown in Table 1. Each component of the formulation was weighed on a Toledo digital scale model 904C/3. Then, the EVAB/EVA-w15 (15 phr), EVA-B/EVA-w25 (25 hr), EVA-B/EVA-w35 (35 phr) composites and EVA-ref were mixed in a Hansen Patent NB25 laboratory banbury with a capacity of $1 \mathrm{~kg}$ in $600 \mathrm{~s}$. After this mixing step, the samples were stored at a temperature of $25^{\circ} \mathrm{C}$ for 24 hours. The samples were then subjected to compression molding in a PHD250I hydraulic press under pressure of $14.71 \mathrm{MPa}$ for $420 \mathrm{~s}$, at $175^{\circ} \mathrm{C}$ in a specific mold to obtain expanded plates samples with dimensions of $0.180 \mathrm{~m} \times 0.160 \mathrm{~m} \times 0.0115 \mathrm{~m}$. The specimens were cut from the expanded plate and cooled to meet both thermal and mechanical characterizations.

\section{Table 1}

\section{Fig. 1}




\section{Characterization}

\section{Particle size distribution}

The EVA-w particle size was obtained by laser diffraction using a Cilas laser diffraction analyzer in wet mode with distilled water.

\section{Fourier Transform Infrared Spectroscopy (FTIR-ATR)}

Tests were performed with the aid of the Attenuated Total Reflectance (ATR) accessory in the IR Tracer-100 Spectrophotometer, (Shimadzu), under the following conditions: Mode: Transmittance, Region: 4000 - $600 \mathrm{~cm}^{-1}$, Resolution: $4 \mathrm{~cm}^{-1}$, Scans: 40 .

\section{Rheological properties}

EVA-ref and EVA-B/EVA-w composites were mixed in a Haake Polylab OS equipped with roller blade rotors. $50 \mathrm{~g}$ of the sample was loaded into the mixing head $\left(69 \mathrm{~cm}^{3}\right)$, corresponding to about $70 \%$ of its capacity. To avoid the formation of molecular crosslinking in the EVA-ref compound, as well as in the EVA-B composites, in accordance with [20], the test temperature was $100^{\circ} \mathrm{C}$. To obtain a homogeneous mixture, the mixing time was 10 minutes and the rotor speeds were 20, 3040 and $50 \mathrm{rpm}$. To evaluate the rheological parameters, for each rotor speed, tests repeated twice for average both torque and temperature. The head mixing dimensions used to calculate the rheological parameters were: $\mathrm{Ro}=19.4 \mathrm{~mm}$; $=47.8 \mathrm{~mm}$.

\section{Mathematical approach}

As proposed by $[15,16]$ the approach considers that the torque rheometer presents two adjacent coaxial cylinders (instead of two rotors). The following relationship between the torque (M) and the angular velocity $(\mathrm{S})$ of the roller, is established as shown in Eq.1: $\mathrm{M}=\mathrm{C}(\mathrm{n}) \mathrm{m} S^{\mathrm{n}}$

where $\mathrm{m}$ and $\mathrm{n}$ are the rheological parameters, respectively a consistency index and power law index; $\mathrm{S}$ is the angular velocity; and $\mathrm{C}(\mathrm{n})$ is an expression that correlates geometric factors of the mixing head with the rheological parameter $n$.

$\mathrm{C}(\mathrm{n})$ is determined by Eq. 2, according to [17]: 
$C(n)=2 \pi L R_{0}^{2}\left\lfloor\frac{2}{n\left(\alpha^{\frac{-2}{n}}-1\right)}\right\rfloor^{n}\left(1+b^{(n+1)}\right)$

where $L$ and $R_{o}$ are the respective length and outside radius of the mixing head; $\alpha$ is a parameter that depends on the geometry mixing head, and defined as the relationship between an equivalent inner radius $(\mathrm{Re})$ and $\mathrm{R}_{0} ; b=2 / 3$ represents the relative speed of the two rollers.

Marquez et al. [17] derived an expression 3 to determine $\alpha$, which considers torque curve fitting for various materials to evaluate values of $\alpha$ and $C(n)$ :

$\alpha=0.86-\frac{1.40}{1+\left(\frac{\mathrm{C}(\mathrm{n}) \mathrm{m}+2.72}{1.03}\right)^{2}}$

However, rheological properties are influenced by temperature, so an expression was proposed by [18] to include the test temperature when determining M, as shown in Eq.4:

$\ln \mathrm{M}=\ln (\mathrm{C}(\mathrm{n}) \mathrm{k})+\frac{\Delta \mathrm{E}}{\mathrm{R}} \frac{1}{\mathrm{~T}}+\mathrm{n} \ln \mathrm{S}$

From Eq. 4, the values of $\mathrm{M}, \mathrm{T}$, and $\mathrm{S}$ were adjusted to obtain activation energy $(\Delta \mathrm{E})$, $\mathrm{n}$, and $\operatorname{lnC}(\mathrm{n}) \mathrm{k}$, where $\mathrm{k}$ is a pre-factor.

According to [18], an expression derived from Cheng et al [19] allows correlating the value of $\mathrm{C}(\mathrm{n}) \mathrm{m}$ with: temperature, pre-factor, $\Delta \mathrm{E}$, and the gas constant $(\mathrm{R})$, as shown in Eq. 5:

$\mathrm{C}(\mathrm{n}) \mathrm{m}=\mathrm{C}(\mathrm{n}) \mathrm{k} \exp \left(\frac{\Delta \mathrm{E}}{\mathrm{RT}}\right)$

The rheological parameter $m$ is given by [18]:

$\mathrm{m}=\mathrm{k} \exp \left(\frac{\Delta \mathrm{E}}{\mathrm{RT}}\right)$

From Eq. 5 the value of $\mathrm{C}(\mathrm{n}) \mathrm{m}$ is determined, using the $\operatorname{lnC}(\mathrm{n}) \mathrm{k}$ value obtained in Eq.4. The value of $\alpha$ is calculated by replacing the c(n)m value in Marquez' equation (Eq. 3). 
$\mathrm{C}(\mathrm{n})$ is calculated from Eq. 2 based on the values of $\alpha$ and $n$, and after determining $\mathrm{C}(\mathrm{n}) \mathrm{m}$ and $C(n)$, the rheological parameter $m$ is determined from Eq. 6 [18]:

$$
\mathrm{m}=\frac{\mathrm{C}(\mathrm{n}) \mathrm{m}}{\mathrm{C}(\mathrm{n})}
$$

The average shear $(\bar{\gamma})$, average stress $(\bar{\tau})$, and average viscosity $(\bar{\eta})$ are determined from Marquez' equations [17], as respectively follows from Eqs.8-10, in:

$\bar{\tau}=\alpha m\left[\frac{2 S}{n\left(1-\alpha^{\frac{2}{n}}\right)}\right]^{\mathrm{n}}$

$\overline{\dot{\gamma}}=\frac{2 S \alpha^{\frac{1}{n}}}{n\left(1-\alpha^{\frac{2}{n}}\right)}$

$\bar{\eta}=\frac{\bar{\tau}}{\dot{\dot{\gamma}}}=m\left[\frac{2 S \alpha^{\frac{1}{n}}}{n\left(1-\alpha^{\frac{2}{n}}\right)}\right]^{\mathrm{n}-1}$

Torque rheometer is one of the techniques to investigate the filled rubber processability in the industrial production [11]. An important parameter to determine is the total mixing energy $(\mathrm{Wt})$, determined from the area under the torque vs. time curve during the test [15], that is, in experimental conditions, as follows:

$\mathrm{Wt}=2 \pi \mathrm{N} \int_{\mathrm{t} 2}^{\mathrm{t} 1} M \mathrm{dt}$

where $\mathrm{N}$ is the rotor speed (rpm), $\mathrm{t}_{1}$ and $\mathrm{t}_{2}$ are the respective initial and final times (min), and $\mathrm{M}$ is the mixing toque (N.m).

In addition, the energy of the unitary mixture $(\mathrm{Wu})$ is the total energy consumed to disperse the load in the rubber matrix at a certain level, being calculated as in Eq. 12 [20, 21]:

$\mathrm{Wu}=\frac{\mathrm{Wt}}{\mathrm{Vb}}$ 
Where $\mathrm{Wu}$ is the total mixing energy $(\mathrm{J})$ and $\mathrm{Vb}$ is the head mixing volume $\left(\mathrm{m}^{3}\right)$.

\section{Results and discussion}

\section{Generation of EVA waste from the industrial process}

Fig. 2 presents two midsole production schemes for footwear fabrication; from raw materials weighing to the final product. In the Fig. 2a. the intermediary compound (IC) production steps are shown, while in Fig.2b, micronized EVA waste (EVA-w) (the perspective of this work) as add to midsole manufacturing is shown. Both machinery and consequently production hours may be saved with the development of EVA-B/EVA-w composites.

\section{Fig. 2}

\section{Particle size distribution}

The granulometric distribution was used to show the different sizes of EVA-w resulting from grinding. Figure 3 presents the laser diffraction result of the particle size analysis. It is possible to verify a bimodal distribution of particles, whose highest concentration of particles is between 6 and $65 \mu \mathrm{m}$ with a lower concentration of sizes between 65 and $300 \mu \mathrm{m}$. The cumulative distribution indicates that $10 \%$ of the particles present diameter below $12.47 \mu \mathrm{m}$ and that $50 \%$ have a diameter below $31.83 \mu \mathrm{m}$. In addition, $90 \%$ of the particles have a diameter less than $135.18 \mu \mathrm{m}$. From these data it can be said that the milling treatment efficiently obtained particles considered as coarse. Only $10 \%$ of the particles were larger than $135.18 \mu \mathrm{m}$, and were considered as coarse. The size distribution analysis of the EVA-w revealed an average of micrometric diameter of 53.06 $\mu \mathrm{m}$. For EVA copolymer filled with bamboo charcoal [22], the bamboo charcoal particles size distribution and its average diameter were smaller than those of EVA-w, the rheological properties were assessed by rotational rheometry. Investigation of the rheological properties of composites using torque rheometer data allows a better understanding of their flow behavior during the mixing time [16].

\section{Fig. 3}

\section{FTIR}


The FTIR analysis was performed to verify whether during the processing of the materials using torque rheometer, crosslinking due to temperature and/or shear had occured.

\section{Fig. 4}

Fig. 4 presents the FTIR-ATR spectra of the EVA-ref, EVA-w and EVA-B composites with 15,25 , and $35 \mathrm{phr}$ of EVA-w. It is possible to verify the characteristic bands of the EVA copolymer. The bands at 2916, 2850, 1430, and $716 \mathrm{~cm}^{-1}$ refer to the ethylene group in the copolymer, that is, the deformations of the $\mathrm{C}-\mathrm{H}$ group. The bands in 1740,1235 , and $1020 \mathrm{~cm}^{-1}$, on the other hand, refer to the copolymer ester group [23, 24]. The band at $1647 \mathrm{~cm}^{-1}$ is characteristic of $\mathrm{C}=\mathrm{C}$ bonds and is related to unsaturation of the crosslinking in the EVA waste (injection twigs and unused midsole) [25, 26]. It can be seen that EVA-w presented $1647 \mathrm{~cm}^{-1}$ band, which represents the crosslinking due to the micronization process. When the EVA-w is added to EVA-B, there is a displacement of this band to lower frequencies, mainly for the EVA-B-w35.

Using the carbonyl band that appears at $1740 \mathrm{~cm}^{-1}$ for EVA-ref as a guide, there is no variation in the $15 \mathrm{phr}$ composite, but in the 25 and $35 \mathrm{phr}$ samples there are shifts to 1732 and $1733 \mathrm{~cm}^{-1}$, respectively. The shift towards lower frequencies of the carbonyl band is indicative of the presence of a conjugated ester, that is, $\mathrm{C}=\mathrm{O}-\mathrm{C}=\mathrm{C}$, showing that EVA-W is also crosslinked. The $870 \mathrm{~cm}^{-1}$ band can be attributed to the presence of carbonate based inorganic fillers, (in addition to the $1430 \mathrm{~cm}^{-1}$ band) overlapping the $\mathrm{C}-\mathrm{H}$ group [27]. In the case of the $870 \mathrm{~cm}^{-1}$ band, it is present in EVA-ref and EVA-w, but not in the composites of EVA-B. Moreover, the $1430 \mathrm{~cm}^{-1}$ band has its intensity greatly reduced in the composites. In the EVA-ref preparation process, the waste from the injection sprues and unused midsoles is mixed with EVA with $28 \%$ vinyl acetate at $110{ }^{\circ} \mathrm{C}$ during $9 \mathrm{~min}$, leading the sample to plasticization. On the other hand, EVA-w was provided from micronization process, and it was added to EVA-B in the form of solid particles with an average diameter of $53.06 \mu \mathrm{m}$. As a result, EVA-w has difficult to interact with inorganic fillers, which justifies the almost no appearance of the carbonate band in EVA-B composites. It can be seen that there are EVA-w - EVA-B interactions in the composites with 25 and 35 phr due to the displacement of the carbonyl band to lower frequencies, however there is no new crosslinks. In addition, it appears that with the increase in the 
amount of EVA-w in the composites, the bands referring to the ester group (1740, 1235 and $1020 \mathrm{~cm}^{-1}$ ) became more intense.

According to Shafeeq and Unnikrishnan [28] when there is a decrease in the intensity of the bands related to the respective symmetrical and asymmetric vibrations of $\mathrm{CH}$ at 2916 and $2850 \mathrm{~cm}^{-1}$, the decrease may be a consequence of cross-link formation through hydrogen abstraction. As shown in Fig. 4, the opposite occurs, there is greater intensity in these bands as the content of EVA-w is increased in the composites. Thus, given the adopted experimental conditions, during processing in the torque rheometer there was no composite cross-linking.

\section{Mixing of the Composites}

With the torque rheometer, when evaluating a generic torque vs. time curve, in initial moments, an abrupt increase in the torque occurs, which is required for feeding of the cold polymer into the mixer. With increasing time, torque decreases and reaches a steady state, this signifies the establishment of mixture homogeneity. The torque variation over the mixing time occurs due to the work required to promote mixing, that is, it represents the resistance that the material offers to the force applied [29]. The EVA-ref compound reached a steady state in three minutes, as shown in Fig. 5a indicating that homogeneity occurred during the first minutes of mixing. For EVA-B/EVA-w composites, the torquetime curves first showed the wetting of EVA-w by EVA-B, followed by decreasing curves characterized by the complete dispersion of EVA-w in EVA-B. Dolezal et al. [20] observed just after the first peak, a secondary peak in the torque curve of the rubber/carbon black compound being attributed to the breakdown of the filler agglomerates. However, there is no secondary peaks in the curves of EVA-B composites, suggesting that little energy was required to separate the particles agglomerates from EVA-w. The torque curve aspects of the present work are in accordance with Nakajima [30], indicating that a simple mixture or an extensive mixture of the EVA-B/EVA-w composites may have occurred. When the torque curves of EVA-B/EVA-w are compared with [31] for EVA/ Silica nanoparticle, a narrower peak width was observed in the shortest times for EVA-B composites, indicating a more homogeneous mixture, without internal friction that is caused by the presence of inorganic nanoparticles. Fig. $5 \mathrm{~b}$ presents temperature curves for the EVA-ref and EVA-B composites. We note that the thermal 
profiles at steady state are practically the same between the composites, and only a slight decrease is observed in the $15 \mathrm{phr}$ composite.

\section{Fig.5}

\section{Processability of the Composites}

The processability of the EVA-ref and EVA-B composites was evaluated by tests performed at $50 \mathrm{rpm}$ for $10 \mathrm{~min}$. From Eq. 11 the unit mixing energy $(\mathrm{Wu})$ was calculated for the composites and results are shown in Table 2. The addition of the EVA-w helped decrease the $\mathrm{Wu}$ of the EVA-B composites, enabling a mixing process with less energy expenditure, suggesting then that there was a dispersion of EVA-w particles in the EVA$\mathrm{B}$ matrix. This assumption is in line with the discussions above about the torque-time curves of these composites. The width at half height of the torque peak $(\mathrm{dx})$ shown Table 2 reveals lower values for the composites compared to the EVA-ref, confirming the lower energy used to mix them. The lower $\mathrm{Wu}$ values observed for composites may be related to the increase in free volume with a consequent increase in molecular mobility, as pointed out by Weber et al. [11]. The difference between the torque stabilization temperature (Tstab) and the test temperature (Ttest) was considered to obtain the $\Delta \mathrm{T}$ values for the samples, being shown in Table 2. It can be seen that the values of $\Delta \mathrm{T}$ are the same for all composites, indicating that little mechanical work was necessary for processing due to the weak interfacial interaction between the constituents of the composites.

\section{Table 2}

\section{Evaluation of rheological properties}

The rheological behavior of particulate polymer composites is quite different from that of pure polymers. The characteristics of the particles, such as size distribution, shape, and concentration, play an important role in modifying the flow resistance, viscosity, nonNewtonian parameters, and the microstructure of the particulate composites $[32,33]$. In this sense, before deciding on the addition of particulate material to the polymer matrix to improve its properties, it is very opportune investigate its rheological response to better understand its processability. The average torque and temperature of the EVA-ref and EVA-B composites were obtained using the mixing procedure described in the Mathematical approach section. The angular velocity (S) was calculated by multiplying the rotor speed (rpm) by $(2 \pi / 60)$. Slight variations in T values were observed between the 
EVA-ref and EVA-B composites. In relation to M, the composites with 15 and $25 \mathrm{phr}$ showed values lower than EVA-ref compound, while EVA-B with 35 phr presents an M value equal to that of the EVA-ref. The $15 \mathrm{phr}$ composite was highlighted for presenting the lowest $\mathrm{M}$ values of all the samples.

\section{Table 3}

Fig. 6 presents the $n$ parameter for the samples obtained using Eq. 4 by multiple linear regression analysis. EVA-ref presents intense non-Newtonian behavior, the addition of EVA-w increases the value of $n$, mainly for the composite with $25 \mathrm{phr}$. The lower values of $n$ infer that the experimental conditions used prevented crosslinking in the EVA-ref molecules, and agree with the FTIR results. In according with [23], an increase in maleic anhydride grafted ethylene/EVA viscosity was due to chain extension and crosslinking reactions. The crosslink formation occurs through a dicumyl peroxide radical activity mechanism, which when thermally activated, releases peroxide radicals. From that point, the hydrogen bonded to the tertiary carbon of the acetate group is abstracted, and the reaction continues until it ends, when the EVA macro-radicals react with each other [31, 34, 35]. The torque-time curves of EVA-B/EVA-w composites were reduced with the addition of EVA-w, mainly for the15 phr composite in agreement with [35], who did not observe an increase in the stabilized torque of a poly (ethylene-stat-vinyl), and argues that there was no crosslink formation during mixing performed at $120^{\circ} \mathrm{C}$. Fig. 6 also shows the values of $m$ parameter for the composites obtained using Eq. 6. It is noticed that the consistency index of EVA-ref compound was higher than that of the EVA-B composites. Further, among them, the $m$ parameter presents a tendency to increase with EVA-w. According to $[36,37]$ from these rheological parameters, the EVA-B/EVA-w composites can be classified as pseudoplastics or as possessing shear-thinning behavior, with the potential to produce complex pieces of shoe midsole.

\section{Fig. 6}

From Fig. 7, using Eqs. 8 and 9 respectively, the average shear stress is plotted against the average shear rate. The response of the shear stress with the increase in the shear rate demonstrates that the relationship between $\bar{\gamma}$ and $\bar{\tau}$ is practically linear, ensuring that the rheological behavior of EVA-ref and EVA-B composites follows powerlaw rheological model as also verified for EVA/diamond nanocomposites [38]. It can be seen that for lower values of $\overline{\dot{\gamma}}$, the $15 \mathrm{phr}$ composite presents lower values of $\bar{\tau}$ than 
does EVA-ref, yet $\bar{\tau}$ values increase for $\bar{\gamma}$ values above of $24 \mathrm{~s}^{-1}$. On the other hand, adding both 25 and 35 phr of EVA-w increase $\bar{\tau}$ values in relation to EVA-ref, but a smaller increase was observed for the $35 \mathrm{phr}$ composite compared to the $25 \mathrm{phr}$ composite. The composites with 25 and $35 \mathrm{phr}$ concentrations present higher $\bar{\tau}$ values (Fig.7), and unit mixing energies (Wu) compared to the $15 \mathrm{phr}$ composite, as shown in Table 2.

Fig. 8 presents the average viscosity in relation to the average shear rate; variables respectively obtained using Eqs.7-9. For all samples, the pseudoplastic behavior was observed, represented by the decrease in viscosity and an increase in shear rate. The verified $n$ values demonstrate the sensitivity of the EVA-ref and EVA-B composite viscosities and shear rates. As compared to the EVA-ref compound, addition of EVA-W at 25 and $35 \mathrm{phr}$ increases composite viscosity slightly, and also produces the same pseudoplastic behavior as the 15 phr composite. Thus, the EVA-B/EVA-w composites evaluated in this work presented little change in rheological properties as compared to the EVA-ref compound. This result is important, since it reflects potential uses that avoid compromising midsole processability.

\section{Fig.7}

\section{Fig. 8}

\section{Conclusion}

The rheological properties obtained using torque rheometry provided substantial information on recycling footwear industry EVA waste. In this work, a micronized process was used to obtain micrometric size particles of EVA waste with average diameter of $53.06 \mu \mathrm{m}$. From FTIR-ATR analysis, no crosslinking reactions occur during processing in the torque rheometer, neither in the EVA-B composites nor in the EVA-ref. The composites of EVA-B-w25 and EVA-B-w35 showed shifts for bands 1732 and 1733 $\mathrm{cm}^{-1}$, being indicative of some interactions between EVA-w and EVA-B. The homogeneity in the mixture of composites occurred in $3 \mathrm{~min}$, with little energy consumption as represented by the unit mixing energy $(\mathrm{Wu})$, making the processability easier. The non-Newtonian index $(n)$ revealed pseudoplastic behavior for the mixtures, which when coupled with the low consistency index $(m)$ values yields a perspective of complete mold filling during midsole injection. The average shear stress values indicated that 15 ph of EVA-w composite can be processed under the same conditions as the 
industrial compound (EVA-ref). However, higher shear stresses were required to process composites with higher EVA-w concentrations. The average shear viscosity confirmed shear rate sensitivity in the composites, and higher viscosity values for composites with higher EVA-w concentrations. This work contributes to the rheological study of EVAB/EVA-w composites, revealing that in the footwear industry, recycling EVA waste is feasible, and brings energy savings and processability to EVA-B composites.

\section{Acknowledgments}

The authors gratefully acknowledge the financial/technical support from Indústria Alpargatas S/A (a shoes and sporting goods company) and the technical support provided by the Materials Engineering Department Laboratories and Renewable Energy Engineering Course of the Federal University of Paraiba.

\section{Declaration of interests}

The authors declare that they have no known competing financial interests or personal relationships that could have appeared to influence the work reported in this paper.

\section{References}

1. Wu XL, Huang WM, Tan HX (2013) Characterization of shape recovery via creeping and shape memory effect in ether-vinyl acetate copolymer (EVA). J Polym Res 20:. https://doi.org/10.1007/s10965-013-0150-4

2. Gilby GW et al (1982) Ethylene-vinil acetate copolymers. In: Developments of rubber technology, 3th ed. Applied Science Publishers Ltd, London, p 101

3. Choi SS, Chung YY (2020) Simple analytical method for determination of microstructures of poly(ethylene-co-vinyl acetate) using the melting points. Polym Test 90:106706. https://doi.org/10.1016/j.polymertesting.2020.106706

4. Nigel J. Mills (2007) Polymer Foams Handbook: Engineering and Biomechanics Applications and Design. Butterworth-Heinemann

5. Maiti M, Jasra RV, Kusum SK, Chaki TK (2012) Microcellular foam from ethylene vinyl acetate/polybutadiene rubber (EVA/BR) based thermoplastic elastomers for footwear applications. Ind Eng Chem Res 51:10607-10612. https://doi.org/10.1021/ie300396m

6. Liu CP, Wang MK, Xie JC, Zhang WX, Tong QS (2013) Mechanochemical 
degradation of the crosslinked and foamed EVA multicomponent and multiphase waste material for resource application. Polym Degrad Stab 98:1963-1971. https://doi.org/10.1016/j.polymdegradstab.2013.07.019

7. Ramarad S, Khalid M, Ratnam CT, Chuah L, Rashmi W (2015) Waste tire rubber in polymer blends: A review on the evolution, properties and future. Prog Mater Sci 72:100-140. https://doi.org/10.1016/j.pmatsci.2015.02.004

8. Zanchet A, Carli LN, Giovanela M, Crespo JS, Scuracchio CH, Nunes RCR(2009) Characterization of microwave-devulcanized composites of ground SBR scraps. J Elastomers Plast 41:497-507. https://doi.org/10.1177/0095244309345411

9. Shi Y, Liu F, Wang Z (2018) Mullins effect and its reversibility for compatibilised thermoplastic elastomers based on high-density polyethylene/waste ground rubber tyre powder under compression mode. Plast Rubber Compos 47:373-380. https://doi.org/10.1080/14658011.2018.1509041

10. Correia JR, Almeida NM, Figueira JR (2011) Recycling of FRP composites: Reusing fine GFRP waste in concrete mixtures. J Clean Prod 19:1745-1753. https://doi.org/10.1016/j.jclepro.2011.05.018

11. Weber T, Oliveira MG, Zeni M, Crespo JS, Nunes RCR (2008) Processability of revulcanizable SBR compositions. Polym Bull 61:217-224. https://doi.org/10.1007/s00289-008-0937-3

12. Alkaya E, Demirer GN (2014) Sustainable textile production: A case study from a woven fabric manufacturing mill in Turkey. J Clean Prod 65:595-603. https://doi.org/10.1016/j.jclepro.2013.07.008

13. Lopes D, Ferreira MJ, Russo R, Dias JM (2015) Natural and synthetic rubber/waste - Ethylene-Vinyl Acetate composites for sustainable application in the footwear industry. J Clean Prod 92:230-236. https://doi.org/10.1016/j.jclepro.2014.12.063

14. Luna CBB, Araújo EM, Siqueira DD, Morais DDS, Filho EAS, Lia Fook MV (2020) Incorporation of a recycled rubber compound from the shoe industry in polystyrene: Effect of SBS compatibilizer content. J Elastomers Plast 52:3-28. https://doi.org/10.1177/0095244318819213

15. Zhang A, Wang L, Zhou Y (2003) A study on rheological properties of carbon black extended powdered SBR using a torque rheometer. Polym Test 22:133-141. https://doi.org/10.1016/S0142-9418(02)00061-2

16. Ceraulo M, Botta L, Scaffaro R, Mistretta MC, La Mantia FP (2014) Prediction of the flow curves of thermoplastic polymer/clay systems from torque data. Polym 
Test 37:12-18. https://doi.org/10.1016/j.polymertesting.2014.04.003

17. Marquez A, Quijano J, Gaulin M (1996) A calibration technique to evaluate the power-law parameters of polymer melts using a torque-rheometer. Polym Eng Sci 36:2556-2563. https://doi.org/10.1002/pen.10655

18. Zhang DW, Li YJ, Feng YH, Qu JP, He HZ, Xu BP (2011) Effect of initial fiber length on the rheological properties of sisal fiber/polylactic acid composites. Polym Compos 32:1218-1224. https://doi.org/10.1002/pc.21141

19 Cheng B, Zhou C, Yu W, Sun X (2001) Evaluation of rheological parameters of polymer melts in torque rheometers. Polym Test 20:811-818. https://doi.org/10.1016/S0142-9418(01)00008-3

20. Dolezal PT, Johnson PS (1980) Contribution of Power Profiles to Mixing Efficiency. Rubber Chem Technol 53:252-269. https://doi.org/10.5254/1.3535039

21. Li BY (2000) The Manufacture and Application of Carbon Black. Press of Chemistry Industry of China. Press Chem Ind China 237-242, 335-337

22. Belaïd S, Boiteux G, Cassagnau P (2013) Rheological and electrical properties of EVA copolymer filled with bamboo charcoal. Rheol Acta 52:75-84. https://doi.org/10.1007/s00397-012-0669-z

23. Hoang T, Chinh NT, Trang NTT, Hang TTX, Thanh DTM, Hung DV, Ha CS, A M (2013) Effects of maleic anhydride grafted ethylene/vinyl acetate copolymer (EVA) on the properties of EVA/silica nanocomposites. Macromol Res 21:12101217. https://doi.org/10.1007/s13233-013-1157-8

24. Adelnia H, Bidsorkhi HC, Ismail AF, Matsuura T (2015) Gas permeability and permselectivity properties of ethylene vinyl acetate/sepiolite mixed matrix membranes. Sep Purif 146:351-357. https://doi.org/10.1016/j.seppur.2015.03.060

25. Zattera AJ, Bianchi O, Oliveira RVB, Canto LB, Ferreira CA, Zeni M (2005) Characterization of EVA residues from the shoe industry and post-consumer urban-waste polyethylenes. Cell Polym 24:139-158. https://doi.org/10.1177/026248930502400303

26. Sasikala A, Kala A (2018) Thermal Stability and Mechanical Strength Analysis of EVA and Blend of EVA with Natural Rubber. Mater Today Proc 5:8862-8867. https://doi.org/10.1016/j.matpr.2017.12.318

27. Andersen FA, Brečević L (1991) Infrared spectra of amorphous and crystalline calcium carbonate. Acta Chem Scand 45:1018-1024. 
https://doi.org/10.3891/acta.chem.scand.45-1018

28. Shafeeq VH, Unnikrishnan G (2020) Experimental and theoretical evaluation of mechanical, thermal and morphological features of EVA-millable polyurethane blends. J Polym Res 27:. https://doi.org/10.1007/s10965-020-2027-7

29. Abdoos H, Khorsand H, Yousefi AA (2014) Torque rheometry and rheological analysis of powder-polymer mixture for aluminum powder injection molding. Iran Polym J (English Ed 23:745-755. https://doi.org/10.1007/s13726-014-0268-1

30. Nakajima N (1982) Energy Measures of Efficient Mixing. Rubber Chem. Technol. 55:931-947

31. Bianchi O, Oliveira RVB, Fiorio R, Matins JN, Zattera AJ, Canto LB (2008) Assessment of Avrami, Ozawa and Avrami-Ozawa equations for determination of EVA crosslinking kinetics from DSC measurements. Polym Test 27:722-729. https://doi.org/10.1016/j.polymertesting.2008.05.003

32. Magalhães Da Silva SP, Lima PS, Oliveira JM (2016) Rheological behaviour of cork-polymer composites for injection moulding. Compos Part B Eng 90:172-178. https://doi.org/10.1016/j.compositesb.2015.12.015

33. Ma Y, Qi F, Chen M, Chen X, Qin J, Tang M (2017) Study on viscoelastic, crystallization, and mechanical properties of HDPE/EVA/Mg(OH) 2 composites. Polym Compos 38:1221-1226. https://doi.org/10.1002/pc.23686

34. Bianchi O, Fiorio R, Martins JN, Zattera AJ, Scuracchio CH, Canto LB(2009) Crosslinking kinetics of blends of ethylene vinyl acetate and ground tire rubber. $\mathbf{J}$ Elastomers Plast 41:175-189. https://doi.org/10.1177/0095244308095015

35. Bianchi O, Martins JDN, Fiorio R, Oliveira RVB, Canto LB (2011) Changes in activation energy and kinetic mechanism during EVA crosslinking. Polym Test 30:616-624. https://doi.org/10.1016/j.polymertesting.2011.05.001

36. Agrawal P, Araújo APM, Lima JCC, Cavalcanti SN, Freitas DMG,Farias GMG, Ueki MM, Mélo TJA(2019) Rheology, Mechanical Properties and Morphology of Poly(lactic acid)/Ethylene Vinyl Acetate Blends. J Polym Environ 27:1439-1448. https://doi.org/10.1007/s10924-019-01445-8

37. Kugimoto D, Kouda S, Yamaguchi M (2021) Modification of Poly(Lactic Acid) Rheological Properties Using Ethylene-Vinyl Acetate Copolymer. J Polym Environ 29:121-129. https://doi.org/10.1007/s10924-020-01856-y

38. Amini M, Ramazani SAA, Haddadi SA, Kheradmand A (2019) Mechanical, rheological and oxygen barrier properties of ethylene vinyl acetate/diamond 
nanocomposites for packaging applications. Diam Relat Mater 99:107523. https://doi.org/10.1016/j.diamond.2019.107523 
Table 1 Formulations of EVA-ref and EVA-B/EVA-w composites.

\begin{tabular}{|c|c|c|c|c|c|c|}
\hline Materials & $\begin{array}{c}\mathrm{IC} \\
(\mathrm{wt} \%)\end{array}$ & $\begin{array}{r}\text { EVA-B } \\
\text { (phr) }\end{array}$ & $\begin{array}{c}\text { EVA-ref } \\
(\text { phr })\end{array}$ & $\begin{array}{c}\text { EVA-B- } \\
\text { w15 } \\
\text { (phr) }\end{array}$ & $\begin{array}{c}\text { EVA-B- } \\
\text { w25 } \\
\text { (phr) }\end{array}$ & $\begin{array}{c}\text { EVA-B- } \\
\text { w35 } \\
\text { (phr) }\end{array}$ \\
\hline $\begin{array}{c}\text { Residue injection sprues and } \\
\text { unusable soles }\end{array}$ & 60.00 & - & - & - & - & - \\
\hline $\begin{array}{c}\text { Ethylene-vinyl-acetate (EVA) } \\
\text { with } 28 \mathrm{wt} \% \text { of VA }\end{array}$ & 40.00 & 24.00 & 24.00 & 24.00 & 24.00 & 24.00 \\
\hline $\begin{array}{c}\text { Ethylene-vinyl-acetate (EVA) } \\
\text { with } 19 \mathrm{wt} \% \text { of VA }\end{array}$ & - & 41.00 & 41.00 & 41.00 & 41.00 & 41.00 \\
\hline Ethylene Butene Copolymer & - & 35.00 & 35.00 & 35.00 & 35.00 & 35.00 \\
\hline Flow agent & - & 1.00 & 1.00 & 1.00 & 1.00 & 1.00 \\
\hline Peroxide & - & 1.60 & 1.60 & 1.60 & 1.60 & 1.60 \\
\hline Expansion agent & - & 2.70 & 2.70 & 2.70 & 2.70 & 2.70 \\
\hline Calcium carbonate & - & 5.60 & 5.60 & 5.60 & 5.60 & 5.60 \\
\hline Zinc oxide & - & 2.00 & 2.00 & 2.00 & 2.00 & 2.00 \\
\hline EVA-w & - & & - & 15.00 & 25.00 & 35.00 \\
\hline
\end{tabular}


Table 2 Unit mixing energy $(\mathrm{Wu})$, total mixing energy $(\mathrm{Wt})$ obtained in the Torque Rheometer

\begin{tabular}{cccccc}
\hline Designation & $\mathrm{Wt}(\mathrm{J})$ & $\mathrm{Wu}\left(\mathrm{J} / \mathrm{m}^{3}\right)$ & $\mathrm{dx}$ & $\mathrm{T}_{\text {stab }}(\mathrm{N} . \mathrm{m})$ & $\Delta \mathrm{T}$ \\
\hline 0 & 191.29 & $318.8 \times 10^{4}$ & 0.3918 & 123.31 & 23.31 \\
$15 \mathrm{phr}$ & 170.33 & $283.8 \times 10^{4}$ & 0.2454 & 122.22 & 22.22 \\
$25 \mathrm{phr}$ & 179.39 & $298.8 \times 10^{4}$ & 0.2737 & 123.37 & 23.37 \\
$35 \mathrm{phr}$ & 182.39 & $303.9 \times 10^{4}$ & 0.2835 & 123.53 & 23.37
\end{tabular}

$\mathrm{dx}$ : torque peak width at half height; $\Delta \mathrm{T}$ : Temperature build-up during mixing; Tstab: torque stabilization temperature. 
Table 3 Average Torque and temperature of EVA-ref and EVA-B/EVA-w composites

\begin{tabular}{|c|c|c|c|c|c|}
\hline \multicolumn{2}{|c|}{ Designation } & $\begin{array}{c}2.10 \\
\left(\mathrm{rad}^{-1}\right)\end{array}$ & $\begin{array}{c}3.15 \\
\left(\mathrm{rad}^{-1}\right)\end{array}$ & $\begin{array}{c}4.20 \\
\left(\operatorname{rad}^{-1}\right)\end{array}$ & $\begin{array}{c}5.25 \\
\left(\mathrm{rad}^{-1}\right)\end{array}$ \\
\hline \multirow[t]{2}{*}{ EVA-ref } & $\mathrm{T}(\mathrm{K})$ & 383.69 & 387.97 & 392.36 & 396.46 \\
\hline & M (N.m) & 14.29 & 15.61 & 16.85 & 17.78 \\
\hline \multirow[t]{2}{*}{$15 \mathrm{phr}$} & $\mathrm{T}(\mathrm{K})$ & 383.42 & 387.35 & 391.15 & 395.05 \\
\hline & M (N.m) & 12.76 & 13.98 & 15.12 & 15.82 \\
\hline \multirow[t]{2}{*}{$25 \mathrm{phr}$} & $\mathrm{T}(\mathrm{K})$ & 384.07 & 388.02 & 392.10 & 396.00 \\
\hline & M (N.m) & 13.59 & 14.82 & 16.17 & 16.65 \\
\hline \multirow[t]{2}{*}{$35 \mathrm{phr}$} & $\mathrm{T}(\mathrm{K})$ & 384.36 & 388.41 & 392.42 & 396.56 \\
\hline & M (N.m) & 14.16 & 15.40 & 16.62 & 17.28 \\
\hline
\end{tabular}


Figure Captions

Fig. 1 EVA waste samples: (a) injection sprues; (b) unused midsoles; (c) small pieces of milled midsoles $(\cong 10 \mathrm{~mm})$; (d) micronized EVA-w from injection sprues and unused midsoles.

Fig. 2 Footwear production industrial process routine: a) without using EVA waste (EVA-w) in the process: 1. Weighing of raw materials; 2.Kneader Mix; 3.Extrusion and Pelleting; 4. Injection of EVA midsoles; 5.Waste of unusable midsoles and injection sprues; 6.Weighing waste + virgin EVA resin- Intermediate compound (IC); 7. Kneader mix of IC; 8. Extrusion and pelleting; 9. Adding IC in EVA-B(EVA-ref). b) using micronized EVA waste (EVA-w) in the process: 1. Weighing of raw materials; 2. Kneader Mix; 3. Extrusion and Pelleting; 4. Injection of EVA midsoles; 5. Waste of unusable midsoles and injection sprues; 6. Micronization of waste (EVA-w); 7. Adding EVA-w in EVA-B.

Fig. 3 Particles distribution of EVA waste.

Fig. 4 FTIR-ATR: EVA-ref compound and EVA-B composites using EVA-w at 15, 25 and $35 \mathrm{phr}$.

Fig. 5 The EVA-ref compound and EVA-B composites with 15, 25 and 35 phr of EVAw: a) Mixing torque-time curves and b) Temperature-time curves at $50 \mathrm{rpm}$.

Fig. 6 Variation of $n$ and $m$ with increasing EVA-w concentrations in the EVA-B composites. A waste content equal to $8 \mathrm{phr}$ correspond to the EVA-ref compound.

Fig. 7 Average shear stress vs. average shear rate for EVA-ref and its composites. A waste content equal to $8 \mathrm{phr}$ correspond to the EVA-ref compound.

Fig. 8 Average shear viscosity vs. the Average of shear rate for EVA-ref and EVA-B composites. A waste content equal to $8 \mathrm{phr}$ correspond to the EVA-ref compound. 


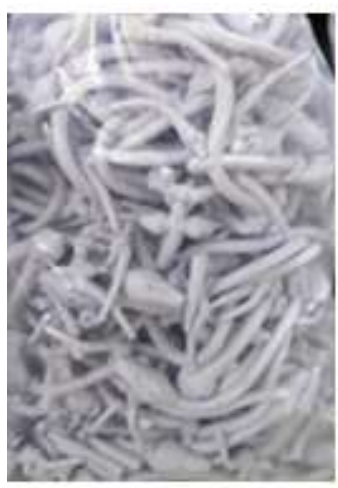

(a)

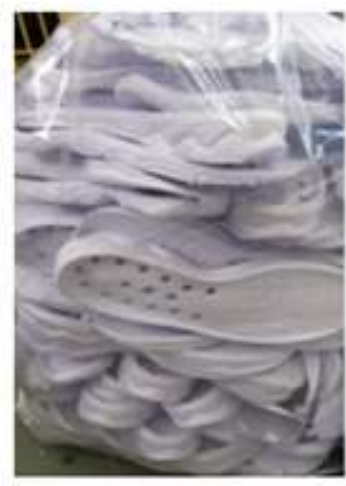

(b)

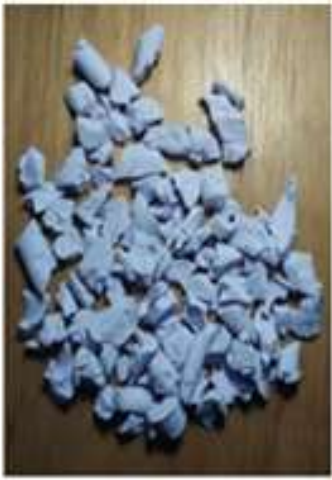

(c)

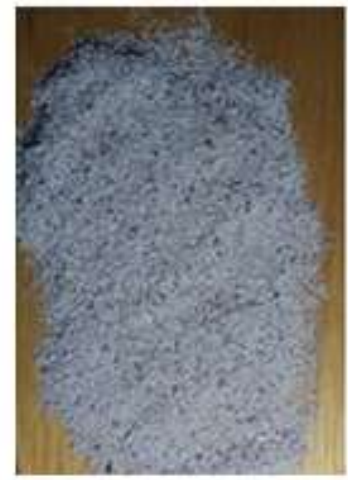

(d)

Fig. 1 


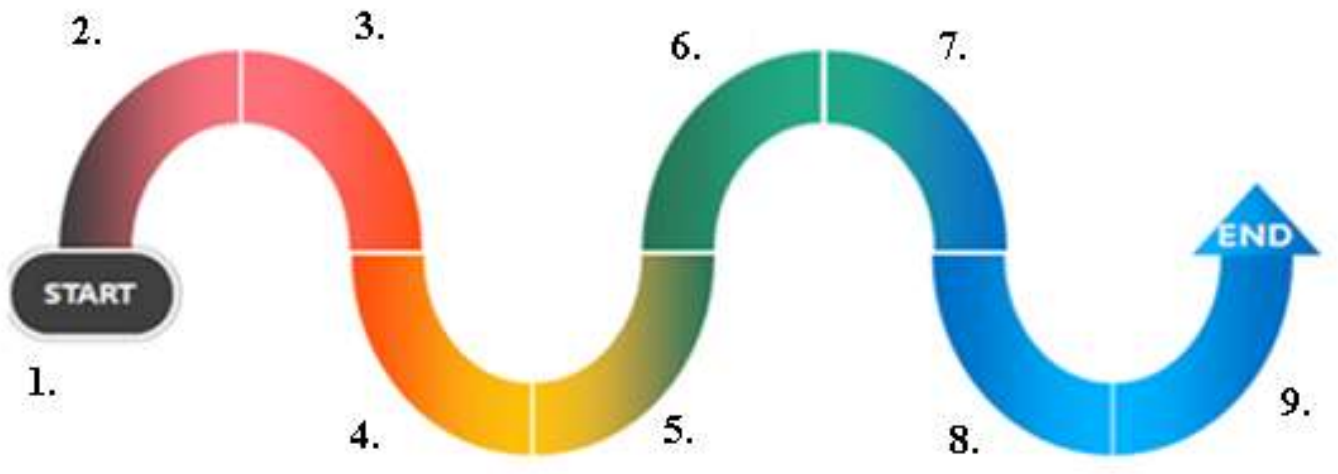

a)

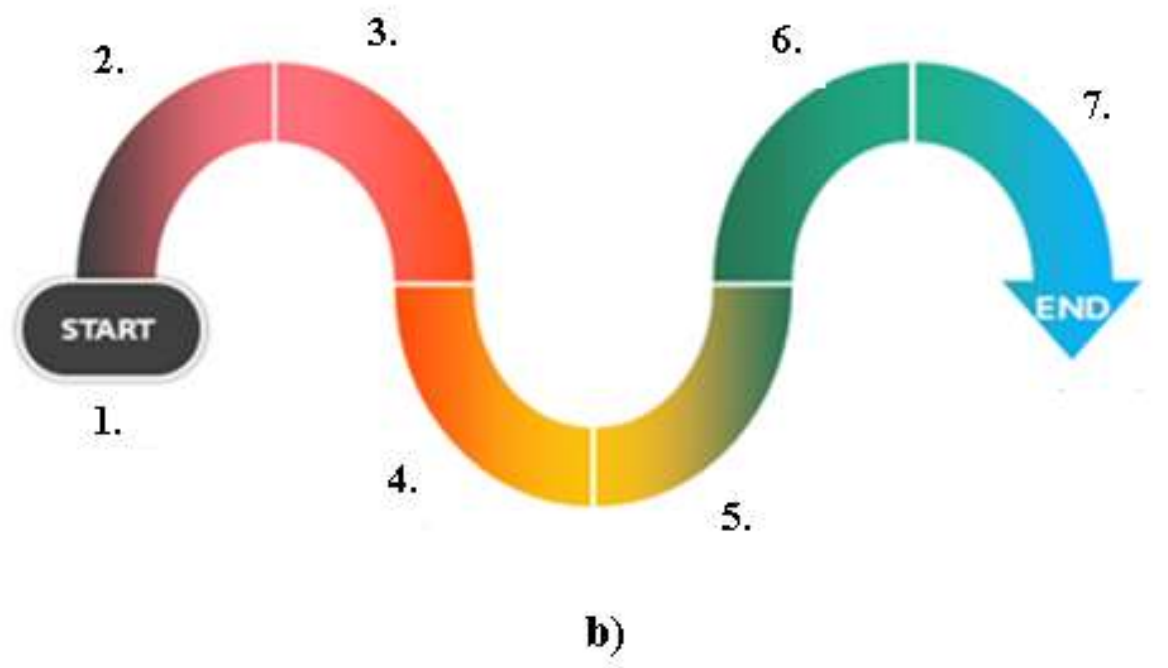

Fig. 2 


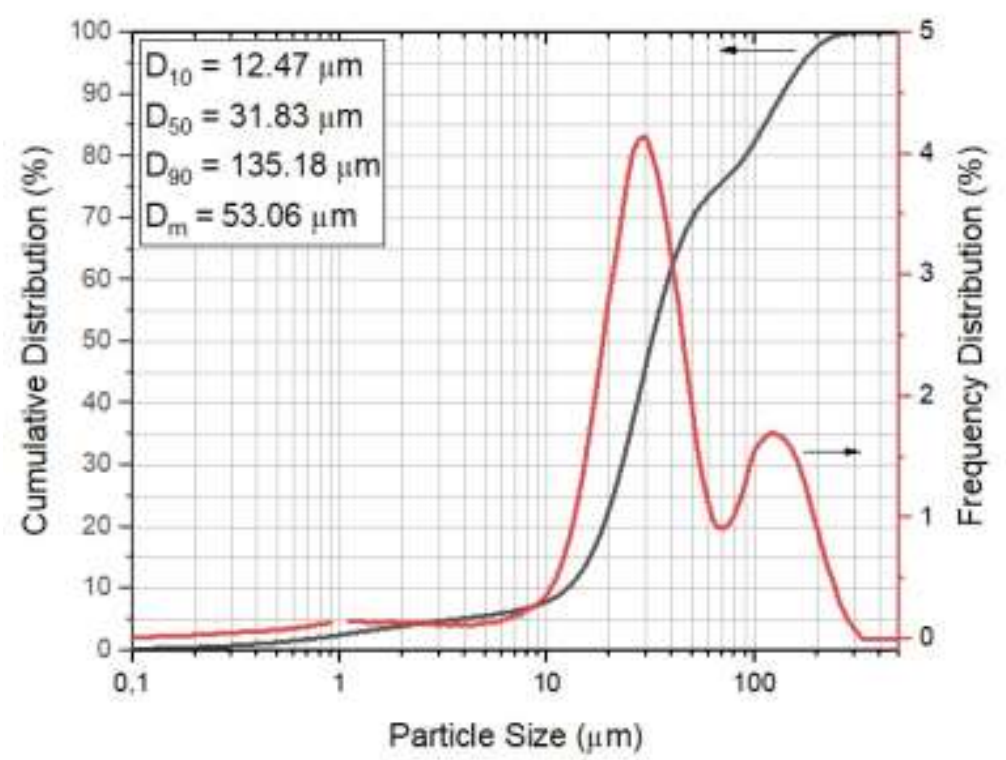

Fig. 3 


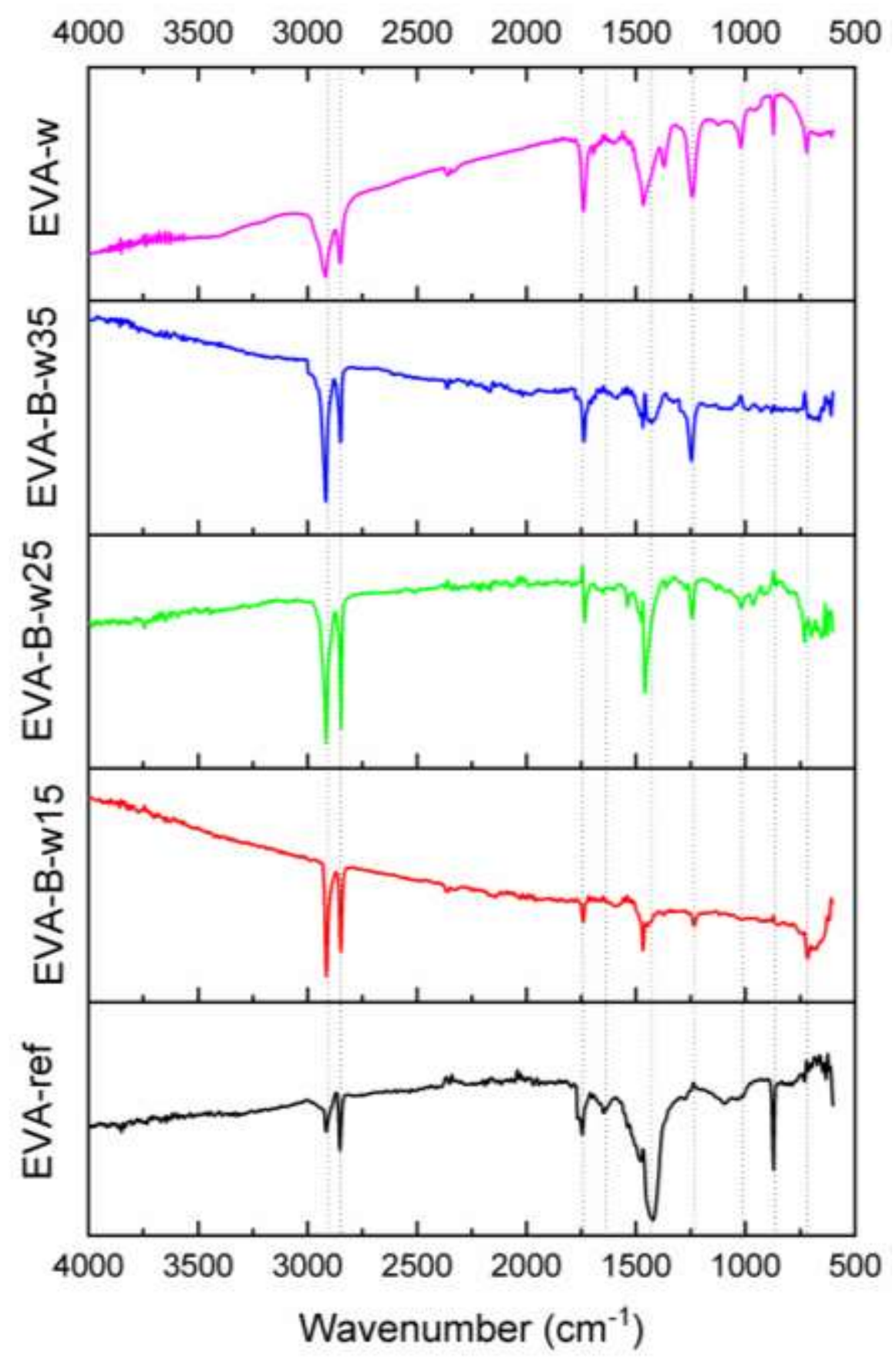

Fig. 4 


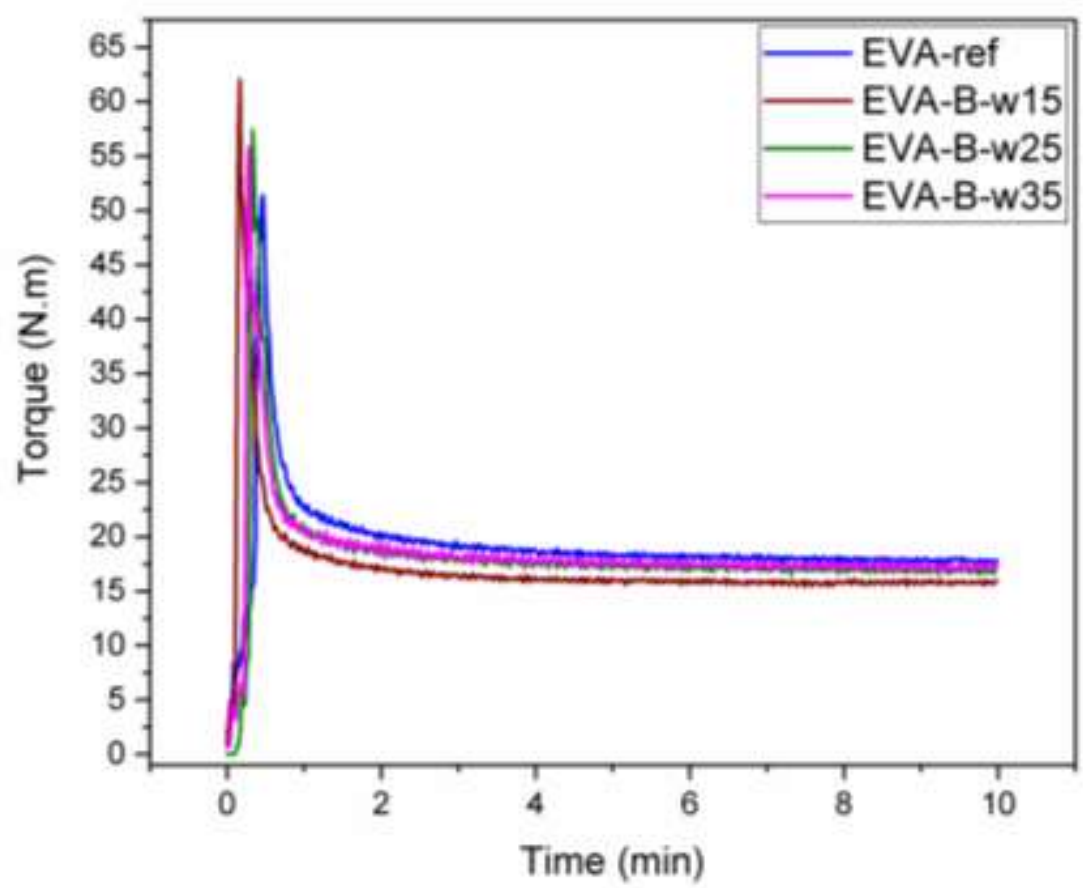

a)

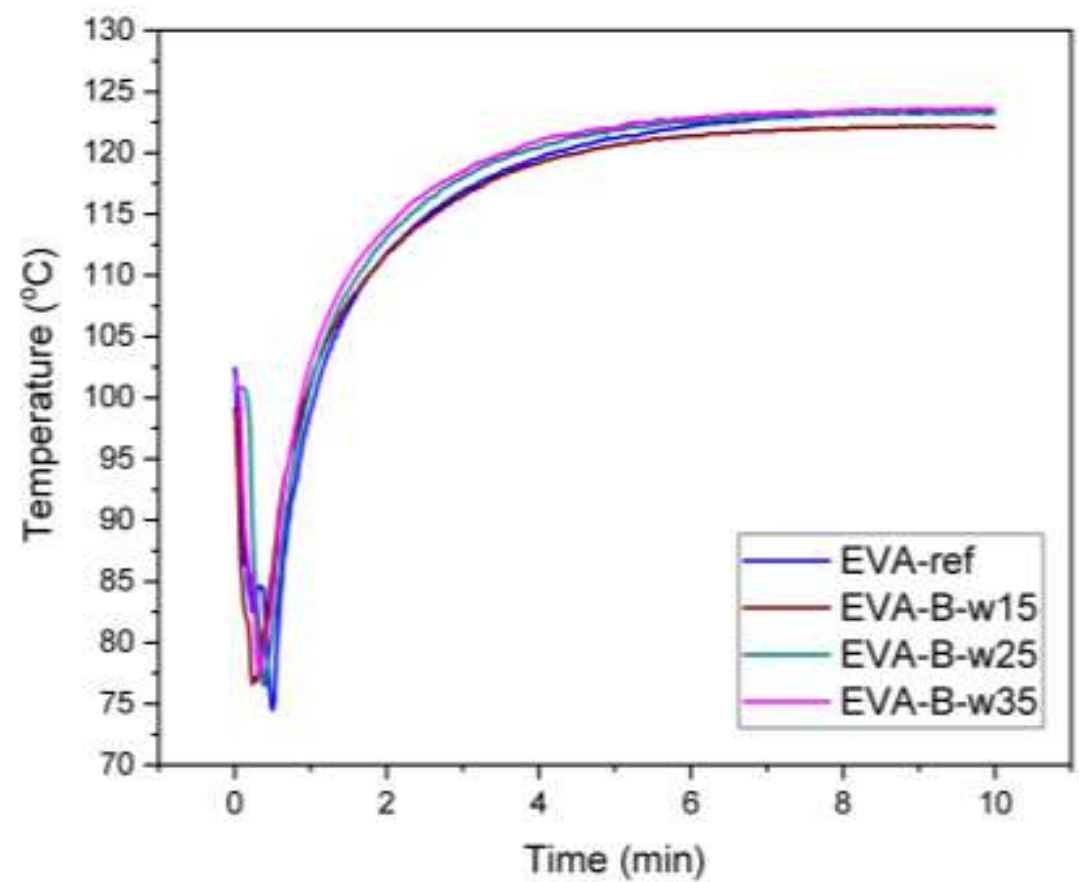

b)

Fig. 5 


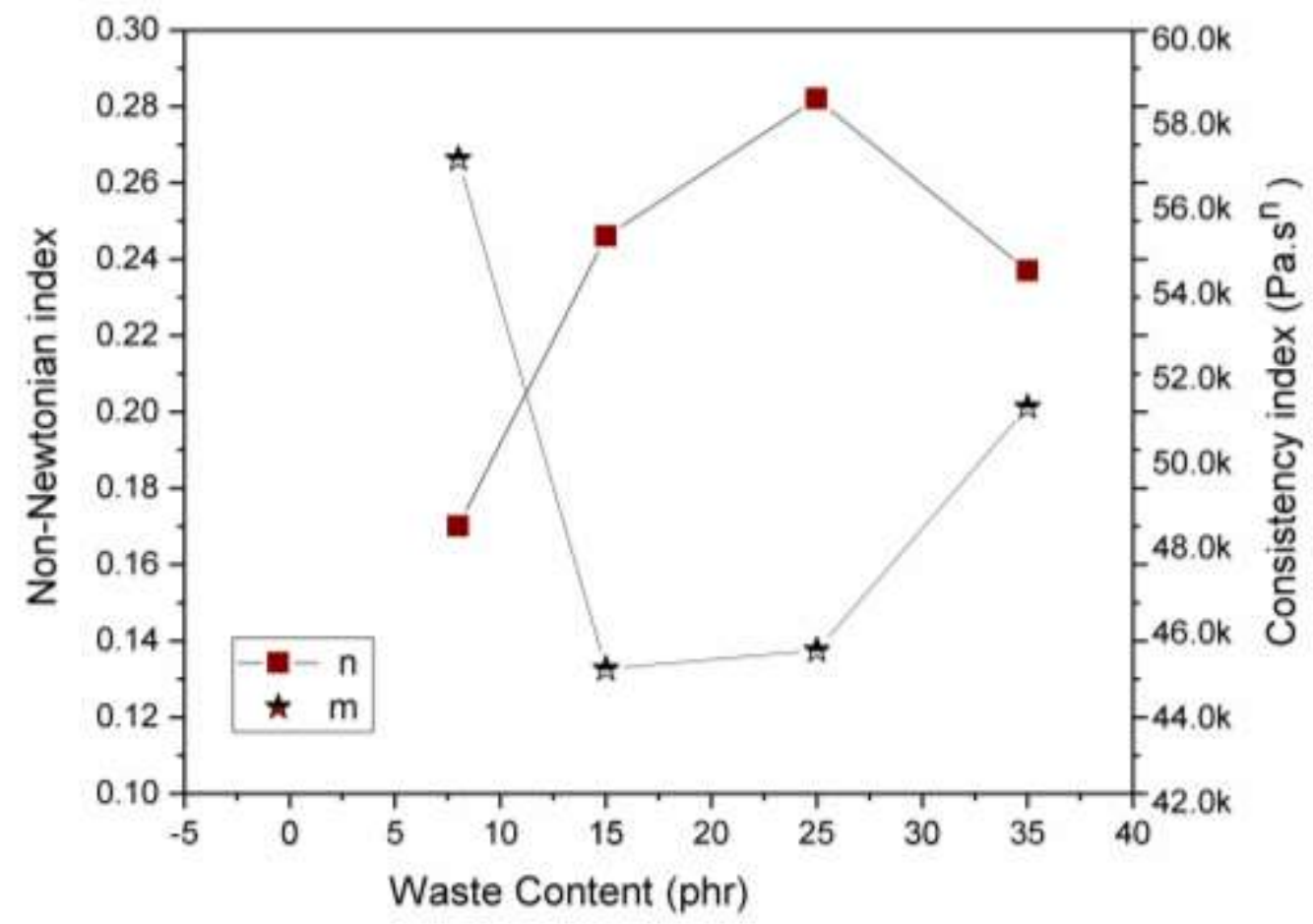

Fig. 6 


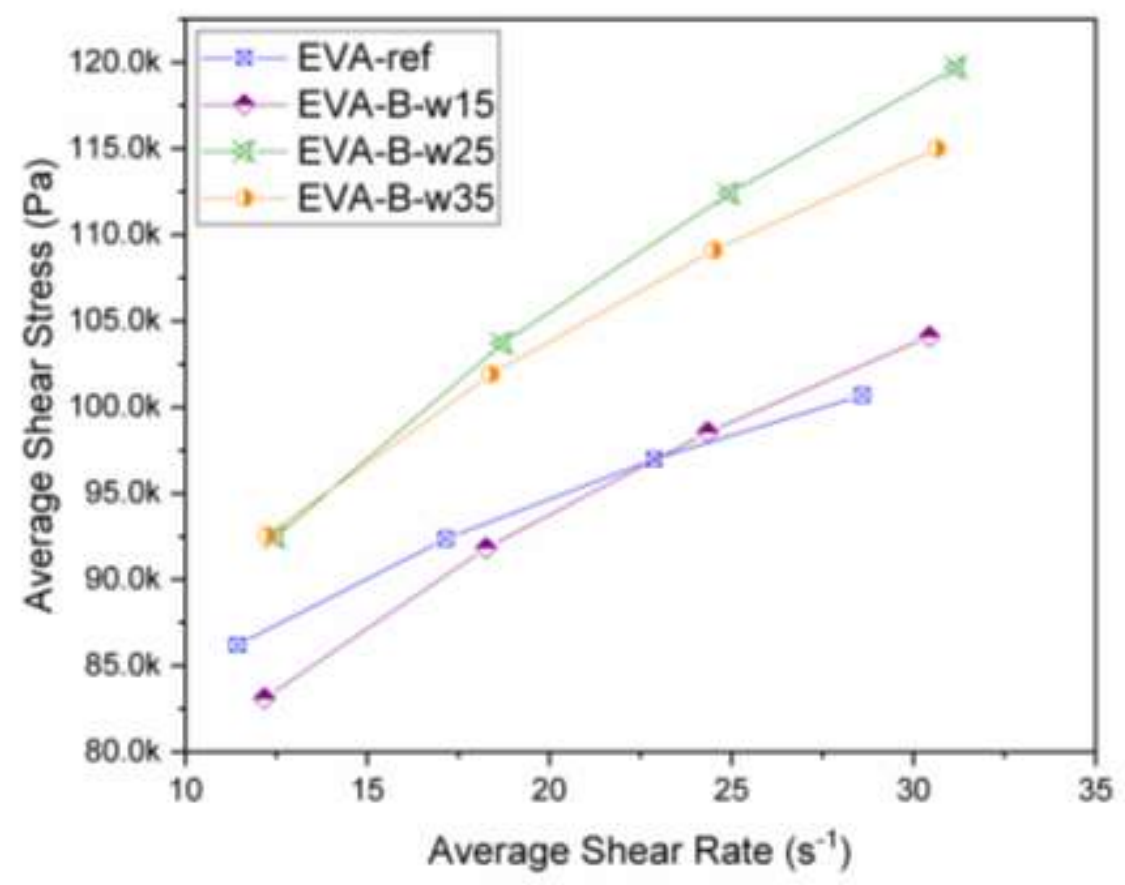

Fig. 7 


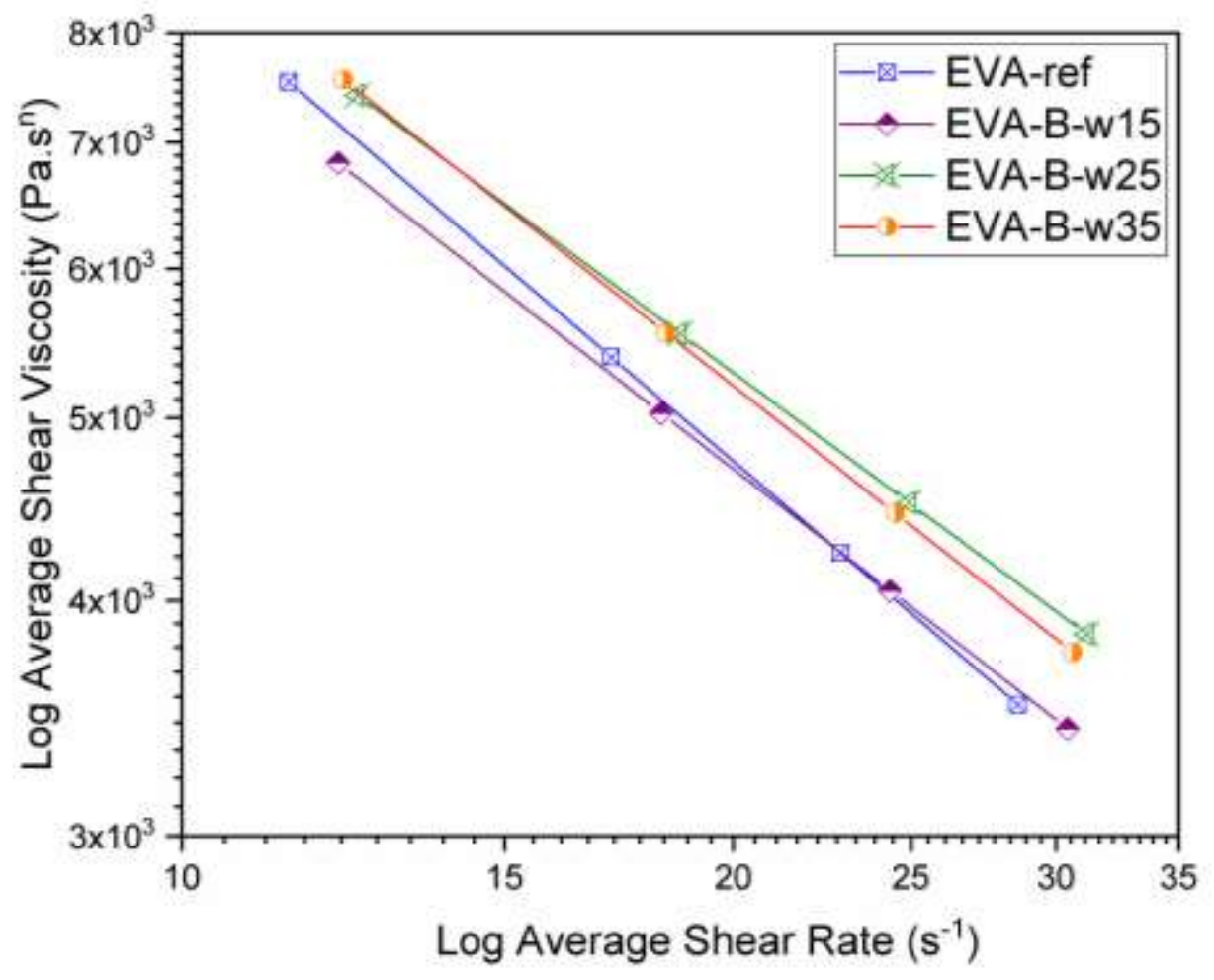

Fig. 8 